\title{
PERANCANGAN SISTEM ANGKAT FORKLIFT DENGAN KAPASITAS ANGKAT 7 TON
}

\author{
Jimmy ${ }^{1)}$, Frans Yusuf Daywin' ${ }^{2)}$ dan Soeharsono ${ }^{3)}$ \\ 1) Program Studi Teknik Mesin Fakultas Teknik Universitas Tarumanagara \\ ${ }^{2)}$ Teknik Pertanian Institut Pertanian Bogor, Bogor \\ 3) Jurusan Teknik Mesin Universitas Trisakti \\ e-mail: soeharsono@trisakti.ac.id
}

\begin{abstract}
Forklift is one of the lifting machines that use to lift and move loads which can move loads with a diffirent height without taking a long time than we lift it by people's strength. The Applications of forklift can be seen at sea port area and loading area in industrial. The design of forklift must be applied to find the hydraulic system and the strenght for the forklift so it will definitely lift the cargo which want to be lifted. Design of forklift consists of design hydraulic system and strength for the forklift.. The design of forklift with 7 tons of capacity will be disscused in this thesis.
\end{abstract}

Keywords: forklift, design, hydraulic.

\section{PENDAHULUAN}

Di dalam lingkungan kita, terdapat sebuah kebutuhan untuk memindahkan sebuah benda dari tempat semula ke tempat tujuan yang diinginkan. Di tempat kerja contohnya, pada area pembangunan, perindustrian, pelabuhan, dan di area-area serupa lainnya, diperlukan sebuah peralatan-peralatan khusus untuk memindahkan bahan-bahan dengan berbagai jenis bentuk dan ukuran yang tidak memungkinkan dipindahkan dengan tenaga manusia. Untuk mempermudah pekerjaan, dibuatlah mesin pemindah bahan yang berfungsi untuk mengangkat dan memindahkan bahan-bahan tersebut.

Dari sekian banyak jenis mesin pemindah bahan yang ada, pesawat angkat merupakan jenis mesin pemindah bahan yang sering digunakan dalam kegiatan pada area konstruksi, pelabuhan, dan perindustrian. Pesawat angkat yang digunakan memiliki ciri, cara kerja , dan dimensi yang berbedabeda sesuai dengan kondisi lapangan, jumlah, bentuk, dan ukuran yang akan diangkut. Forklift adalah contoh dari pesawat angkat yang berfungsi untuk mengangkat dan memindahkan bahan dengan ketinggian yang berbeda yang tidak mampu dipindahkan oleh manusia.

Suatu benda yang diberi beban berat secara terus menerus akan mengalami fatique sehingga benda tersebut akan rusak. Seperti pada forklift ini, jika forklift tidak dirancang dengan dengan baik maka forklift tersebut tidak akan bertahan lama atau akan menyebabkan kecelakaan kerja yang dapat membahayakan jiwa para pekerja. Oleh karena itu, perlu dilakukan penelitian dan perancangan yang bertujuan untuk memperoleh forklift yang kuat dan aman.

\section{METODOLOGI PENELITIAN}

Metodologi penelitian dilakukan agar proses penelitian berjalan dengan sistematis dengan dilakukan beberapa tahapan yaitu : menentukan tujuan dari penelitian, mengumpulkan landasan teori, menentukan prosedur penelitian, dan melakukan perhitungan kekuatan sistem angkat. Spesifikasi teknis forklift berkapasitas 7 ton ditunjukkan pada Tabel 1 dan tampak samping dan depan dari mekanisme angkat forklift ditunjukkan pada Gambar 1 dan 2.

Mekanisme angkat dan jungkit dari forklift merupakan mekanisme yang sangat menentukan unjuk kerja dari forklift. Komponen pada mekanisme angkat dan jungkit antara lain lift cylinder yang berfungsi untuk menaikkan dan menurunkan muatan dan tilt cylinder yang berfungsi untuk menarik muatan, seperti yang ditunjukkan pada Gambar 3 dan 5.

Lift cylinder dirancang agar dapat mengangkat beban sebesar 7 ton sehingga harus dihitung gaya angkat silinder sehingga silinder dapat dipastikan mampu mengangkat beban tersebut. Berdasarkan pada tipe pembuatan rantai, nilai $n$ dapat ditentukan. Perhitungan gaya angkat silinder dapat dihitung dengan menggunakan persamaan: 


$$
F s i l=W a+\frac{W a}{n}
$$

Keterangan :

$F_{\text {sil }}$ : gaya silinder hidrolik $(N)$

$W_{a}$ : besar berat muatan angkat $(N)$

$n$ : efisiensi rantai

Tabel 1. Spesifikasi forklift

\begin{tabular}{ll}
\hline Spesifikasi forklift & \\
\hline Mesin & Izuzu 6BG1 \\
Daya & 114 HP @2000 rpm \\
Transmisi & 2 percepatan maju dan 2 percepatan mundur \\
Bahan bakar & Diesel \\
Dimensi & Pxlxt (3600mm x 1995mm x 2250mm) \\
& Berat kotor $16330 \mathrm{~kg}$ \\
Ban & Ban depan $8.25 \times 15-14 \mathrm{PR}$. \\
& Ban belakang $8.25 \times 15-14 \mathrm{PR}$. \\
Rem & Hidrolik \\
Mekanisme tiang pengangkat & 2 tahap \\
& Ketinggian maksimum $3000 \mathrm{~mm}$ \\
Kapasitas beban & 7 ton \\
Kecepatan angkat & $550 \mathrm{~mm} / \mathrm{s}$ (tanpa beban) \\
& $460 \mathrm{~mm} / \mathrm{s}$ (dengan beban) \\
Kecepatan maju & $18.64 \mathrm{mph}$ (tanpa beban) \\
& $16.16 \mathrm{mph}$ (dengan beban) \\
Kecepatan mundur & $18.64 \mathrm{mph}$ (tanpa beban) \\
& $16.16 \mathrm{mph}$ (dengan beban) \\
\hline
\end{tabular}

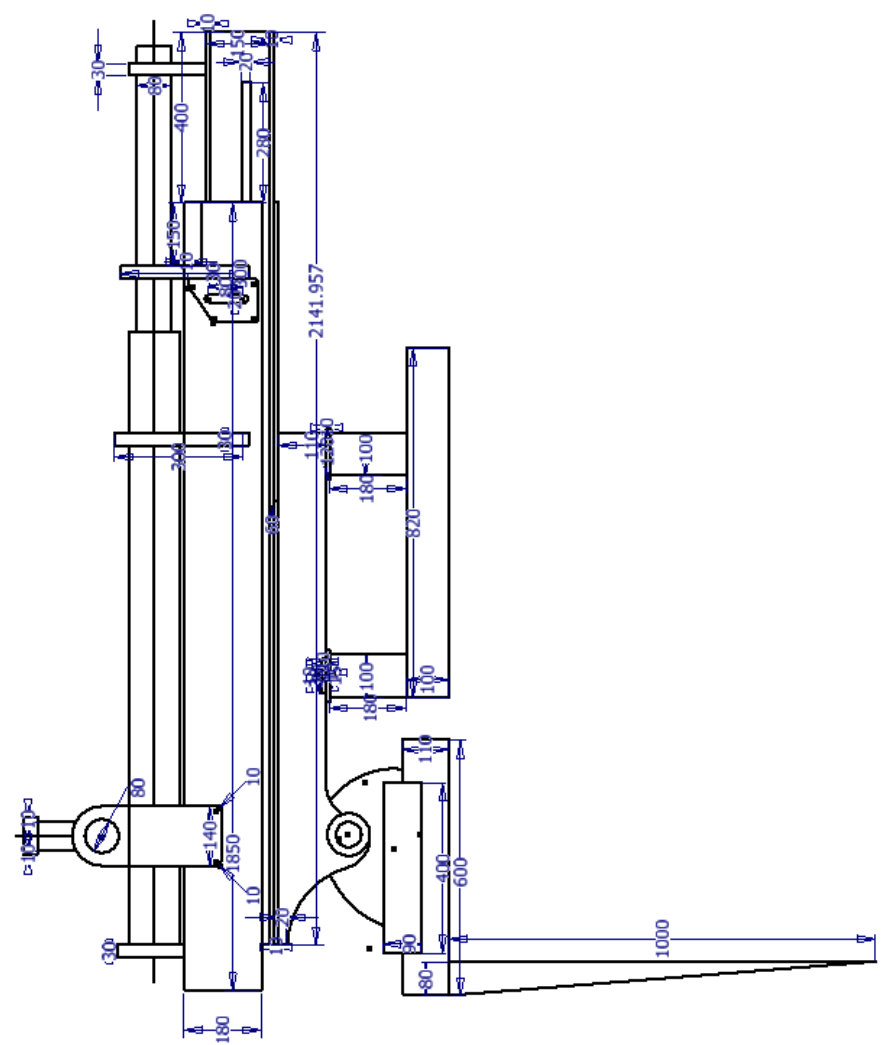

Gambar 1. Sketsa tampak samping sistem angkat forklift dalam satuan $\mathrm{mm}$ 


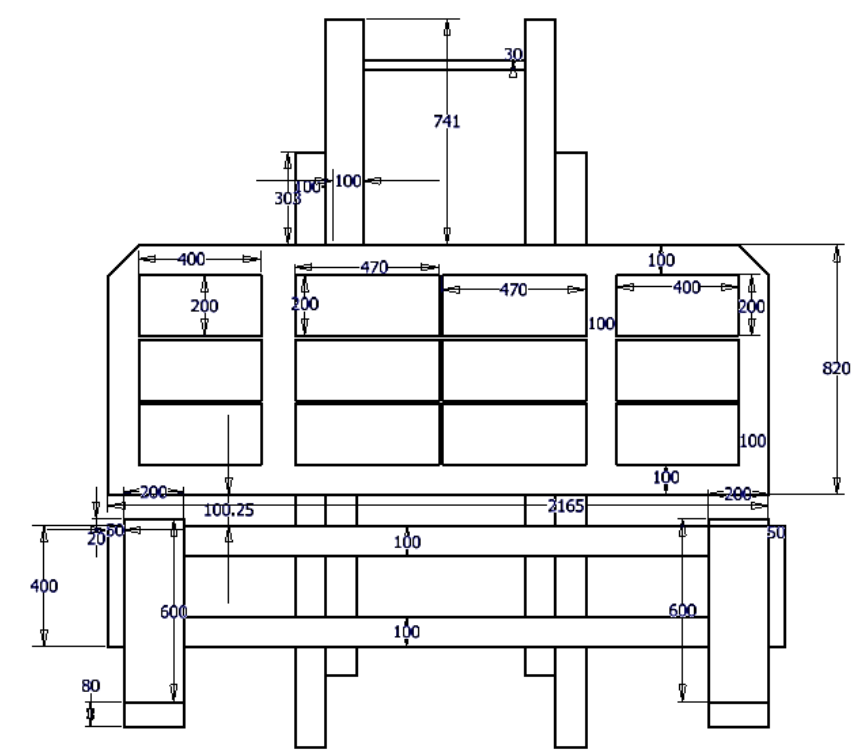

Gambar 2. Sketsa tampak depan sistem angkat forklift dalam satuan mm

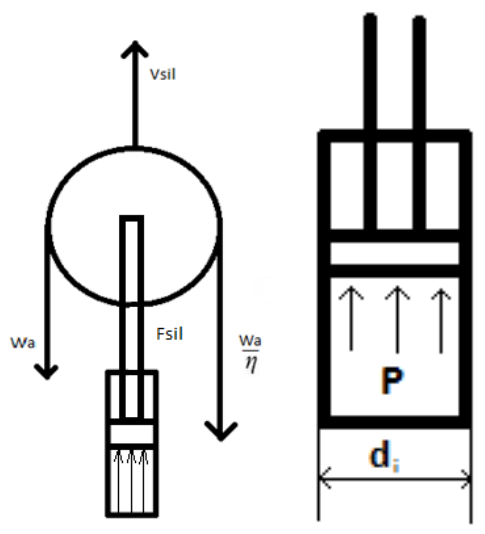

Gambar 3. Mekanisme pengangkatan hidrolik

Pemeriksaan tekanan hidrolik pada lift hidraulic dapat dihitung dengan menggunakan persamaan :

$$
p=\frac{F}{A}
$$

Keterangan :

$$
\begin{array}{lll}
p & : & \text { tekanan hidrolik }(\mathrm{N} / \mathrm{mm}) \\
F & : & \text { gaya silinder hidrolik }(\mathrm{N}) \\
A & : & \text { luas alas silinder hidrolik }\left(\mathrm{mm}^{2}\right)
\end{array}
$$

Sedangkan untuk perhitungan tekanan hidrolik, dibutuhkan luas alas silinder hidrolik. Luas alas silinder hidrolik dapat dihitung dengan persamaan :

$$
A=\frac{\pi}{4} \cdot d^{2}
$$

Keterangan :

A : luas alas silinder hidrolik $\left(\mathrm{mm}^{2}\right)$

$\pi \quad$ : konstanta untuk mencari luas lingkaran

$d$ : diameter lingkaran alas silinder ( $\mathrm{mm})$

Pemeriksaan daya pompa dapat dilakukan dengan menggunakan persamaan :

$$
p=F . V \text {. }
$$


Keterangan:

$p \quad$ : daya pompa $(\mathrm{W})$

$F \quad$ : gaya silinder $(\mathrm{N})$

$V$ : kecepatan angkat silinder $(\mathrm{m} / \mathrm{s})$

Tilt cylinder adalah silinder hidrolik yang dipasang ke bingkai truk dan mast. Tilt cylinder berfungsi untuk membantu dalam menarik beban. Tilt cylinder berfungsi untuk menarik muatan.

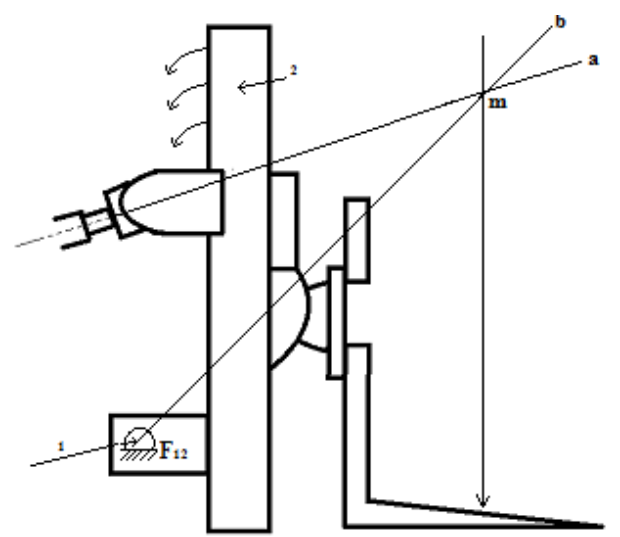

Gambar 4. Mekanisme tilt hydraulic

Tilt cylinder dirancang untuk dapat membantu dalam menarik beban muatan sebesar 7 ton sehingga harus dihitung gaya silinder sehingga silinder dipastikan dapat menarik muatan tersebut. Mencari gaya silinder dapat dihitung dengan menggunakan gambar gaya. Gambar gaya dapat digambar dengan cara meneruskan garis pada arah gaya silinder dan meneruskan garis pada gaya beban sehingga garis gaya silinder dan garis gaya beban dapat bertemu dan berhimpit di titik $\mathrm{m}$. Ada gaya yang bekerja dari frame terhadap mast yaitu gaya $F_{1 / 2}$. Gaya $F_{1 / 2}$ dapat dicari dengan cara menarik garis gaya engsel dengan cara membuat garis panjang dari titik engsel hingga melewati titik m. Sehingga didapat gambar gaya :

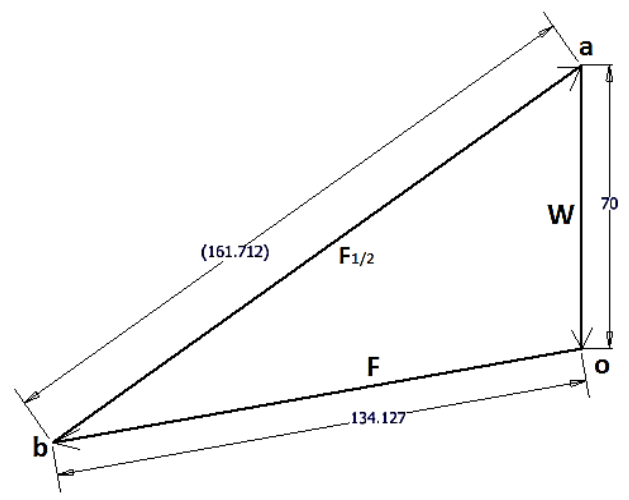

Gambar 5. Gambar poligon gaya

Dari gambar gaya tersebut dapat diambil persamaan untuk mencari besar gaya silinder. Persamaan gaya yang dapat digunakan :

$$
\begin{aligned}
& \Sigma F=0 \\
& \Sigma F=\bar{W} \mapsto \bar{F} \mapsto \bar{F}_{2 / 2}=0 \\
& F=\frac{o b}{o a} . W
\end{aligned}
$$

Keterangan :

$W$ : gaya arah berat muatan $(\mathrm{N})$

$F \quad$ : gaya silinder $(\mathrm{N})$ 
oa : panjang jarak garis muatan (mm)

$o b$ : panjang jaran garis gaya $(\mathrm{mm})$

Tilt cylinder 2 adalah silinder hidrolik yang dipasang ke garpu dan tiang penyangga garpu. Tilt cylinder 2 dirancang khusus agar operator tidak akan kesulitan memindahkan muatan apabila tempat sempit karena tiang mast tidak ikut bergerak.

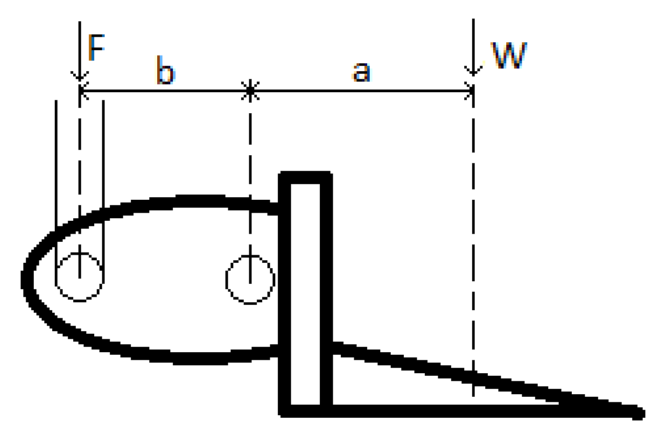

Gambar 6. Mekanisme Tilt Hidraulic 2

Tilt cylinder dirancang untuk dapat membantu dalam menarik beban muatan sebesar 7 ton sehingga harus dihitung gaya silinder sehingga silinder dipastikan dapat menarik muatan tersebut. Mencari gaya silinder dapat dihitung dengan menggunakan persamaan :

$$
W . a=F . b
$$

Keterangan :

$W$ : Muatan angkat $(\mathrm{kg})$

$a \quad$ : Panjang jarak antara silinder dengan engsel (mm)

$F \quad$ : Gaya silinder (N)

$B$ : Panjang jarak antara engsel dengan titik tengah muatan garpu (mm)

Sistem transmisi yang digunakan untuk mekanisme-mekanisme ini adalah transmisi rantai, dengan tipe BL-634. Untuk menghitung tegangan yang terjadi pada rantai maka dapat digunakan persamaan :

$$
\sigma=\frac{F}{A}
$$

Keterangan:

$\sigma:$ Tegangan tarik (Nmm)

$F \quad$ : Gaya tarik yang terjadi pada rantai $(\mathrm{N})$

A : Luas pada rantai $\left(\mathrm{mm}^{2}\right)$

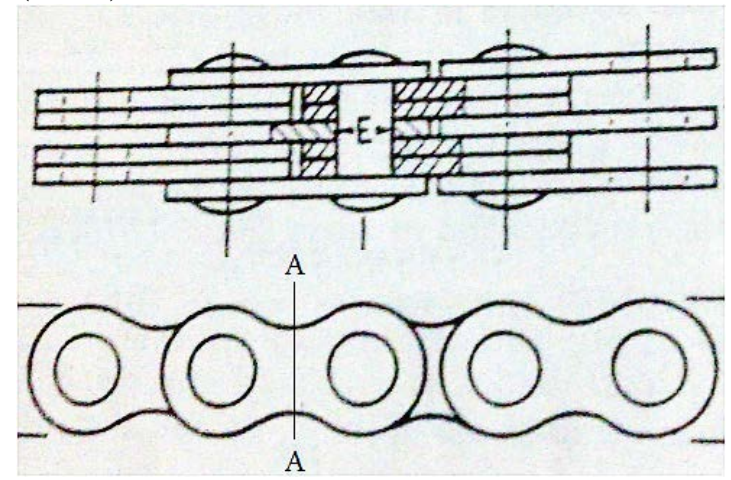

Gambar 7. Sketsa sebuah rantai

Untuk menghitung luas rantai, maka dapat digunakan rumus persegi karena apabila dipotong maka luas pada penampang rantai akan terlihat persegi panjang. Sehingga dapat digunakan persamaan : 


$$
A=p . l
$$

Keterangan :

$$
\begin{array}{lll}
A & : & \text { Luas pada rantai }\left(\mathrm{mm}^{2}\right) \\
p & : & \text { Panjang }(\mathrm{mm}) \\
l & : \text { Lebar }(\mathrm{mm})
\end{array}
$$

\section{Perhitungan Sproket}

Pada forklift berkapasitas 7 ton ini menggunakan sprocket no D60B25H, kekuatan tarik dapat ditentukan. Untuk menghitung tegangan yang terjadi pada rantai dapat dihitung dengan menggunakan persamaan :

$$
\sigma=\frac{M}{W}
$$

Keterangan :

$\sigma:$ Tengangan tarik $\left(\mathrm{N} / \mathrm{mm}^{2}\right)$

$M$ : Momen (Nmm)

$W$ : Tegangan kolom $\left(\mathrm{mm}^{3}\right)$

Sehingga untuk mencari tegangan tarik maka harus dihitung tegangan kolom dan momen yang terjadi. Tegangan kolom dapat dihitung dengan menggunakan persamaan:

$$
W=\frac{1}{6} b \cdot t^{2}
$$

Keterangan :

$$
\begin{aligned}
& W: \text { Tegangan kolom }\left(\mathrm{mm}^{3}\right) \\
& b: \text { Lebar sproket yang telah dipotong }(\mathrm{mm}) \\
& t: \text { Tinggi sproket yang telah dipotong }(\mathrm{mm})
\end{aligned}
$$

Dan untuk mencari momen dapat dihitung dengan menggunakan persamaan:

Keterangan :

$$
M=F \cdot \frac{a}{2}
$$

$M$ : Momen (Nmm)

$F \quad:$ Gaya tarik $(\mathrm{N})$

$a \quad$ : Panjang nilai a (mm)

\section{HASIL DAN PEMBAHASAN}

Besar gaya untuk mendorong lift cylinder dapat dihitung dengan menggunakan Persamaan (1) dengan nilai $\eta=0,9$ sehingga mendapatkan :

$$
\begin{aligned}
& \mathrm{F}=68670 N+\left[\frac{68670 N}{0,9}\right] \\
& \mathrm{F}=144970 \mathrm{~N}
\end{aligned}
$$

Sehingga untuk menghitung daya pompa dapat dihitung dengan menggunakan Persamaan (2) dan mendapatkan:

$$
\begin{aligned}
& \mathrm{p}=68670 \mathrm{~N} \times 0,23 \mathrm{~m} / \mathrm{s} \\
& \mathrm{p}=27 \mathrm{~kW}
\end{aligned}
$$

Untuk menghitung besar berat gaya pada tilt cylinder maka dapat digunakan Persamaan (5) dengan panjang $\mathrm{W}=71,451 \mathrm{~cm}$; panjang $\mathrm{F}=163,308 \mathrm{~cm}$; panjang $\mathrm{R}=166,5 \mathrm{~cm}$; dan besar $\mathrm{W}=7$ ton $=$ $7.000 \mathrm{~kg}$ sehingga didapat:

$$
\begin{aligned}
& F=\frac{134,127 \mathrm{~cm}}{70 \mathrm{~cm}} \times 7000 \mathrm{~kg} \\
& F=13412,7 \mathrm{~kg}
\end{aligned}
$$

Untuk mendapatkan besar gaya tilt cylinder maka harus dikalikan dengan gravitasi sehingga didapatkan:

$$
\begin{aligned}
& F=13412,7 \mathrm{~kg} \times 9,81 \mathrm{~m} / \mathrm{s}^{2} \\
& F=131578,587 \mathrm{~N}
\end{aligned}
$$


sedangkan untuk menghitung daya pompa pada tilt cylinder dapat menggunakan Persamaan (1) dengan $\mathrm{V}=0,2 \mathrm{~m} / \mathrm{s}^{2}$ sehingga didapat:

$\mathrm{p}=131.578,587 \mathrm{~N} \times 0,2 \mathrm{~m} / \mathrm{s}$

$\mathrm{p}=26315,71$ watt

$\mathrm{p}=26,3 \mathrm{~kW}$

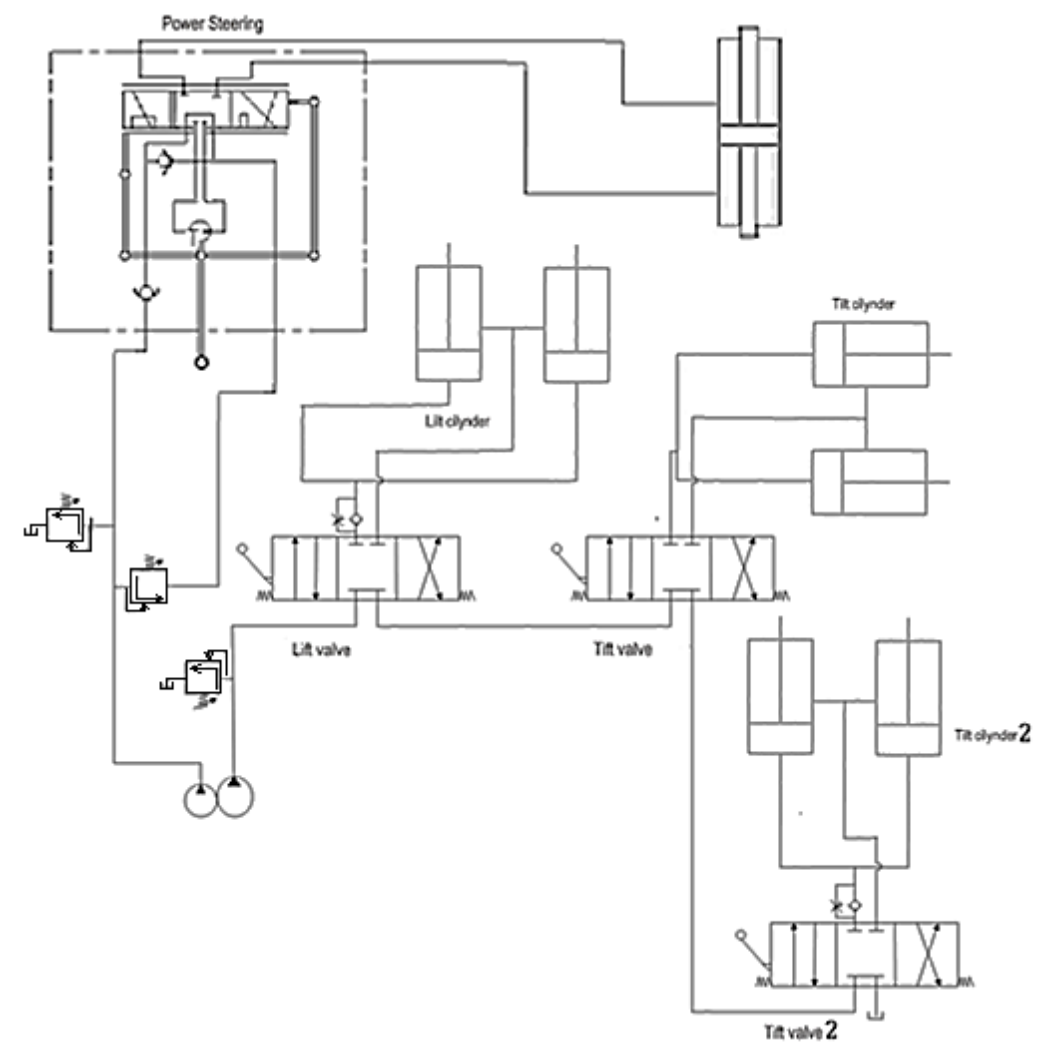

Gambar 8. Rangkaian Hidrolik yang digunakan

Perhitungan besar berat pada $\mathrm{F}$ dapat dilakukan dengan persamaan (6) dengan panjang $\mathrm{b}=$ $25 \mathrm{~cm}$; panjang a $=76 \mathrm{~cm}$; $\mathrm{W}=7$ ton sehingga didapat:

$\mathrm{W} \times \mathrm{a}=\mathrm{F} \times \mathrm{b}$

7 ton $\times 76 \mathrm{~cm}=\mathrm{F} \times 25 \mathrm{~cm}$

$\mathrm{F}=\frac{76 \mathrm{~cm} \times 7 \text { ton }}{25 \mathrm{~cm}}$

$\mathrm{F}=21280 \mathrm{~kg}$

Untuk mendapatkan besar gaya tilt cylinder 2 maka harus dikalikan dengan gaya gravitasi dengan $\mathrm{g}$ $=9,81 \mathrm{~m} /{ }^{\mathrm{s} 2}$ sehingga didapatkan:

$\mathrm{F}=21280 \mathrm{~kg} \times 9,81 \mathrm{~m} / \mathrm{s}^{2}$

$\mathrm{F}=208756,8 \mathrm{~N}$

Sedangkan untuk menghitung daya pompa pada tilt cylinder 2 dapat menggunakan persamaan $(3,4)$ dengan $\mathrm{V}=0,05 \mathrm{~m} / \mathrm{s}^{2}$ sehingga didapat:

$\mathrm{p}_{\mathrm{p}}=208756,8 \mathrm{~N} \times 0,1 \mathrm{~m} / \mathrm{s}$

$\mathrm{p}_{\mathrm{p}}=21 \mathrm{~kW}$

Perhitungan tegangan tarik yang terjadi pada rantai dengan menggunakan Persamaan (7) dan didapat :

$$
\begin{aligned}
& \sigma=\frac{\frac{34335 \mathrm{~N}}{3}}{57,9635 \mathrm{~mm} 2} \\
& \sigma=\frac{11445 \mathrm{~N}}{57,9635 \mathrm{~mm} 2}
\end{aligned}
$$




$$
\sigma=198 \mathrm{~N} / \mathrm{mm}^{2}
$$

Perhitungan tegangan tarik yang diijinkan pada sproket dengan menggunakan Persamaan (9) dan mendapatkan :

$$
\begin{aligned}
\sigma & =\frac{1918688,85 \mathrm{Nmm}}{403,81 \mathrm{~mm} 3} \\
\sigma & =4752 \mathrm{~N} / \mathrm{mm}^{2}
\end{aligned}
$$

\section{KESIMPULAN}

Berdasarkan pengamatan, perhitungan dan analisis yang telah dilakukan, maka diambil kesimpulan yaitu mekanisme pengangkatan sistem angkat forklift dengan efisiensi $=0,9$, jumlah hidrolik adalah 2, dan berdiameter $80 \mathrm{~mm}$. Jenis rantai yang digunakan adalah ISO 606/ ANSI B29.100 dengan beban tarik $=17.000 \mathrm{~kg}$, dan hasil tegangan tarik yang terjadi pada rantai adalah $\sigma_{t}$ $=198 \mathrm{~N} / \mathrm{mm}^{2}$. Beban yang diangkat forklift adalah $7.000 \mathrm{~kg}$, dengan daya pompa untuk sistem angkat $27 \mathrm{~kW}$, daya pompa untuk sistem jungkir 26,3 $\mathrm{kW}$, dan daya untuk sistem jungkir 2 adalah $21 \mathrm{~kW}$. Rangkaian sistem angkat hidrolik yang digunakan adalah rangkaian seri, dengan 3 buah 4/3 directional control valve yang dapat bekerja secara bergantian. Material untuk struktur sproket pada sistem angkat forklift menggunakan steel dengan beban tarik $=17.000 \mathrm{~kg}$, hasil tegangan tarik yang terjadi pada sproket adalah $\sigma_{t} 979 \mathrm{MPa}$

\section{DAFTAR PUSTAKA}

[1]. Conveyor. http://www.automation-supplies.com/modular-plastic-belt-conveyors.html November 2012)

[2]. Directional control valve. http://www.wisc-online.com/objects/ViewObject.aspx? ID=DCE9404

[3]. Dongkrak Hidrolik. http://www.hyjacks.com/n_71100a.jpg (15 November 2012)

[4]. Elevator. http://science.howstuffworks.com/transport/engines-equipment/elevator.htm November 2012)

[5]. [Forklift. http://sparepartforklift.com/hhu

[6]. Gantry Crane. http://www.krhicranes.com/blog/tag/tower-cranes/ (15 November 2012)

[7]. Ir.Soeharsono,M.sc., slide mata kuliah "Hidrolik" Universitas Tarumanagara, Jakarta.

[8]. Khurmi R.S. dan Gupta J.K. A Textbook Of Machine Design. New Delhi : Eurasia Publishing House (PVT.) LTD. 2005

[9]. Rangkaian hidrolik universitas sumatera utara. repository.usu.ac.id/bitstream/... /Chapter\%20II.pdf

[10]. Rangkaian hidrolik US patent. www.patentlens.net/patentlens/patent/US_5617724/

[11]. REX . Components and products for power transmission and material handling. USA:REX CHAINBELT INC.1972

[12]. Sistem Hidrolik. http://m-edukasi.net/online/2008/sistemhidrolik/materi01a.html

[13]. Sproket. http://www.ebay.com/itm/NISSAN-FORKLIFT-CRANKSHAFT-GEARSPROCKET-715-ENGINES-PARTS-1W00/310421167226?pt=LH_DefaultDomain_0\&hash $=$ item48468b1c7a 